\title{
Acute Kidney Injury in Multisystem Inflammatory Syndrome in Children (MIS-C)
}

\author{
Sare Gulfem Ozlu ${ }^{1} \cdot$ Gulsum Iclal Bayhan ${ }^{2,3}$ (I)
}

Accepted: 18 December 2020 / Published online: 3 January 2021

(C) Springer Nature Switzerland AG 2021

Dear Editor,

We have read with great interest the manuscript entitled "Acute Kidney Injury in Multisystem Inflammatory Syndrome in Children (MIS-C): a Case Report" [1].

The authors present a 15-year-old girl who had been diagnosed with acute kidney injury (AKI) due to multisystem inflammatory syndrome in children (MIS-C). We have some concerns about the differential diagnosis of acute kidney injury in this patient. Firstly, urine examination which is a crucial step in the diagnosis of AKI is not mentioned in the text [2]. The existence of hematuria or proteinuria and the density of urine could all be helpful clues for the underlying cause of AKI [2].

The clinical picture described here represents a rapidly progressing course of AKI and a huge number of underlying causes may be responsible for this. Although the patient was dehydrated rather than overhydrated and this might be a clue for prerenal AKI, the possible underlying causes may be more comprehensively discussed before attributing the course to COVID-19. The ultrasonographic findings of this patient were not mentioned in the text. Without urine examination and ultrasound, one cannot complete the diagnostic work-up of AKI. Also, in rapidly progressive courses, renal biopsy should be part of diagnostic investigations.

This article is part of the Topical Collection on Covid-19

Gulsum Iclal Bayhan

gibayhan@gmail.com

1 Department of Pediatric Nephrology, Children's Hospital of Ankara City Hospital, Faculty of Medicine, Yildirim Beyazit University, Ankara, Turkey

2 Department of Pediatric Infectious Disease, Children's Hospital of Ankara City Hospital, Faculty of Medicine, Yildirim Beyazit University, Ankara, Turkey

3 Çocuk Enfeksiyon Kliniği, Ankara Șehir Hastanesi, Çocuk Hastanesi, Çankaya, Turkey
Authors mention the rapid improvement of patient with intravenous immunoglobulin and one dose of bolus methyl prednisolone. A variety of AKI causes may respond to steroids or immune globulin as described in rapidly progressive glomerulonephritis, tubulointerstitial nephritis, and vasculitisrelated glomerulonephritis.

We also want to emphasize that renal involvement has been reported too rarely, even not reported in several MIS-C series [3-6]. We are not sure how reliable it would be to suggest that an extremely rarely reported entity is caused by MIS-C before all possible diagnoses have been ruled out.

Due to the pandemic we are in, the focus of physicians on COVID-19 infection may lead to overdiagnosis of MIS-C. The suppression of inflammation, which can occur for many different reasons, by the IVIG, steroid, and immunomodulatory agents used in the MIS-C treatment, may lead to delay of the correct diagnosis. Therefore, we thought that it is very important to perform the diagnostic study for possible differential diagnosis of MIS-C before starting treatment for MIS-C.

Author's Contribution Bayhan G.I.: concept and design, literature review, writer.

Ozlu S.: critical review, writer.

Data Availability Not applicable.

\section{Compliance with Ethical Standards}

Conflict of Interest The authors declare that there is no conflict of interest.

Ethics Approval Not applicable.

Consent to Participate Not applicable.

Consent for Publication Not applicable.

Code Availability Not applicable. 


\section{References}

1. Lee M, Hilado M, Sotelo S, Opas LM, Im DD. Acute kidney injury in multisystem inflammatory syndrome in children (MIS-C): a case report. SN Compr Clin Med. 2020;2:2899-902.

2. Roy JP, Devarajan P. Acute kidney injury: diagnosis and management. Indian J Pediatr. 2020;87(8):600-7. https://doi.org/10.1007/ s12098-019-03096-y.

3. Feldstein LR, Rose EB, Horwitz SM, Collins JP, Newhams MM, Son MBF, et al. Multisystem inflammatory syndrome in U.S. children and adolescents. N Engl J Med. 2020;383(4):334-46.

4. Abrams JY, Godfred-Cato SE, Oster ME, Chow EJ, Koumans EH, Bryant B, et al. Multisystem inflammatory syndrome in children associated with severe acute respiratory syndrome coronavirus 2 : a systematic review. J Pediatr. 2020;226:45-54.

5. Pouletty M, Borocco C, Ouldali N, Caseris M, Basmaci R, Lachaume N, et al. Paediatric multisystem inflammatory syndrome temporally associated with SARS-CoV-2 mimicking Kawasaki disease (Kawa-COVID-19): a multicentre cohort. Ann Rheum Dis. 2020;79:999-1006.

6. Radia T, Williams N, Agrawal P, Harman K, Weale J, Cook J, et al. Multi-system inflammatory syndrome in children \& adolescents (MIS-C): A systematic review of clinical features and presentation. Paediatr Respir Rev. 2020;S1526-0542(20):30117-2.

Publisher's Note Springer Nature remains neutral with regard to jurisdictional claims in published maps and institutional affiliations. 